\title{
Tipps und Tricks: Hebel für Fixateur externe - Modulartechnik
}

$\square$ Dankward Höntzsch

Dieser Tipp hilft nur dann, wenn bei Ihnen hoffentlich die Modulartechnik für die notfallmäßige und/oder elektive Fixateurmontage Standard ist (Abb.). Für den Fall, dass die Modulartechnik verwendet wird, kann eine erhebliche Hilfe empfohlen werden.

Zunächst wird jeder Teilrahmen wie gewohnt montiert.

An diesen Teilrahmen werden dann temporäre Griffe angebracht. Dies kann ent- weder über die 2 Schanz-Schrauben-Enden passieren oder mit einer Rohr-RohrBacke an dem Rohr des Teilrahmens. Der Griff sollte dann in Längsrichtung und in die Gegenrichtung des jeweiligen proximalen und distalen Knochenfragments zeigen. Je länger desto besser. Mit diesem Griff kann dann gehebelt werden. Noch besser geht es, wenn am Ende dieses Griffs noch ein Querstab aus einer Schanz-Schraube oder einem kurzen Rohr angebracht wird. So hat man auch die Rotation noch besser im „Griff“.
Mit diesen Griffen kann man dann viel effektiver, sanfter, zügiger, kraftvoller und gesteuerter reponieren. Ein sehr großer Vorteil ist, dass die Hände außerhalb des Röntgenstrahls des Bildwandlers liegen, wenn die Reposition nicht nur klinisch, sondern auch radiologisch überprüft wird.

Nach erfolgter Stabilisierung werden diese temporären Griffe dann abgebaut.
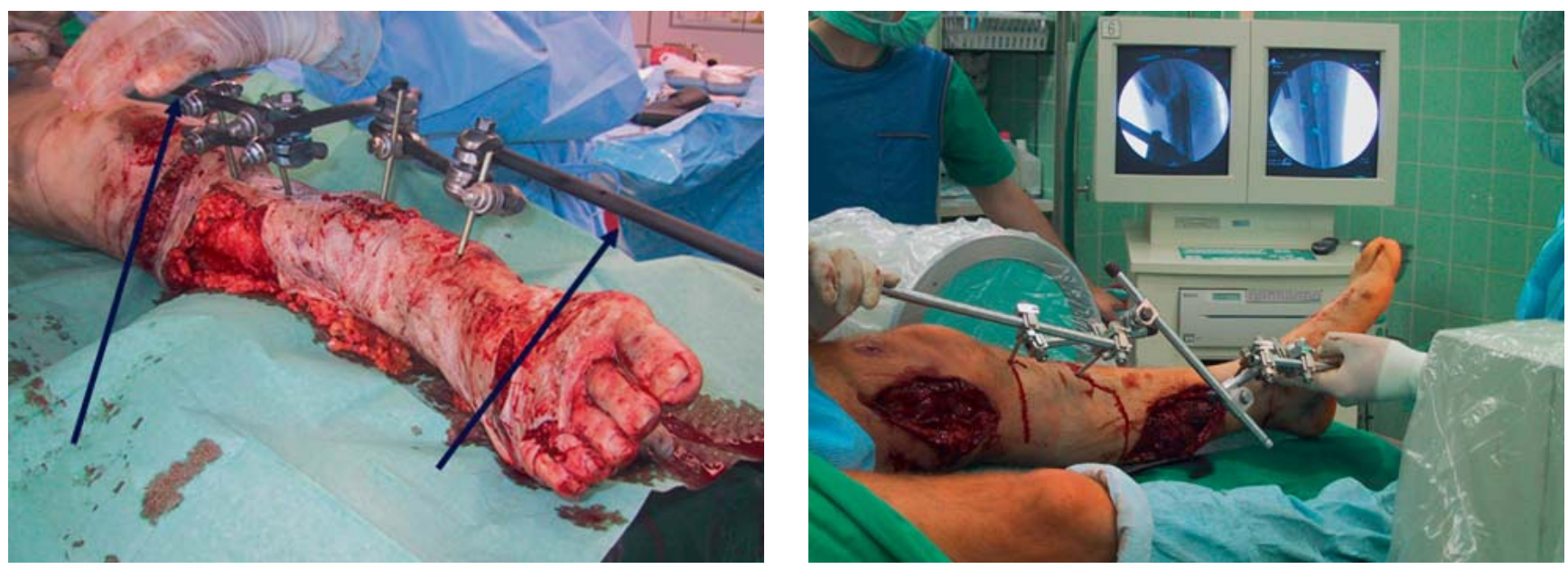

OP-JOURNAL 2016; 32: 159

(c) Georg Thieme Verlag KG Stuttgart · New York DOI http://dx.doi.org/10.1055/s-0042-117126 